\title{
Pengembangan dan validitas Pane Afdal Psychological Condition for Domestic Violance Inventory (PAPC-DVI)
}

\author{
Nurmaida Pane ${ }^{1}$, Afdal Afdal ${ }^{2}$ \\ ${ }^{12}$ Universitas Negeri Padang, Indonesia
}

\begin{tabular}{l}
\hline Article Info \\
\hline Article history: \\
Received Apr 21st, 2020 \\
Revised Mei 22nd, 2020 \\
Accepted Jun 1st, 2020
\end{tabular}

\section{Keyword:}

Kondisi Psikologis

Validitas

Reliabilitas

\begin{abstract}
Cases of domestic violence increase every year where the dominant victim is a wife. Many factors cause victims to receive violence, one of which is caused by psychological conditions. This study aims to develop and validate the inventory of Psychological Conditions of Afdal Pane for Domestic Violence (PAPC-DVI). This inventory will measure assertive behavior and resilience of victims of domestic violence as psychological conditions that cause victims to accept violence. Assertive behavior will measure positive assertiveness, selfaffirmation, and negative assertiveness. resilience will measure equaminity, perseverance, self-reliance, meaningfulness, and existential aloneness. This research was conducted on 90 wives who experienced violence in the city of Padang using purposive sampling techniques. Furthermore, validity was analyzed using Cronbach's alpha item analysis which showed a coefficient $\alpha>$ , 175 , and the data showed that 36 PAPC-DVI items were valid. In addition, the alpha cronbach reliability value was also used to analyze the data and the results showed that the PAPC-DVI reliability coefficient for victims of domestic violence was 0,932 . The results showed that PAPC-DVI in victims of domestic violence is valid in measuring psychological conditions that cause victims to receive violence so that this inventory can help in understanding psychological conditions that cause victims to receive violence and are ready to be used by subsequent researchers.
\end{abstract}

C 2020 The Authors. Published by Indonesian Institute for Counseling, Education and Therapy (IICET). This is an open access article under the CC BY license (https://creativecommons.org/licenses/by/4.0/)

\section{Corresponding Author:}

Afdal Afdal;

Universitas Negeri Padang

Email: afdal@konselor.org

\section{Pendahuluan}

Data Komnas Perempuan tahun 2019 melaporkan jumlah kasus kekrasan dalam rumah tangga (KDRT) meningkat sebesar 6\%, dari 406.178 kasus pada tahun 2018 menjadi 431.471 kasus pada tahun 2019 (Komnas Perempuan, 2020). Penelitian juga menunjukkan bahwa data dominan menjadi korbannya adalah istri (Afdal, 2015). Kasus kekerasan yang semakin meningkat ini disebabkan oleh banyak faktor seperti istri yang tidak berperilaku asertif, dengan mentoleransi kesalahan yang telah diperbuat pasangan dan selalu memaafkannya serta adanya harapan suami akan berubah (Afdal et al., 2019; Anggoman, Y., \& Wirawan, 2002; Benjamin J. Sadock, M. ., \& Virginia A. Sadock, 2005; Chosniah, 2014; Luhulima, 2000; LundbergLove et al., 2006; Twenge, 2001). Selain itu pernikahan yang sudah berlangsung lama (Alizamar, A., Afdal, A., \& Pane, 2019) mengakibatkan banyak istri yang mengembangkan sikap resiliensi dengan kembali dan mempertahankan pernikahannya dikarenakan anak, takut menyandang status janda dan ketergantungan finansial (Ayu et al., 2017; Nurhayati, 2006; Segaf et al., 2009; Soemarno et al., 2017; Sriyanto et al., 2014). Berdasarkan uraian di atas, penulis menyimpulkan bahwa faktor yang mengakibatkan korban menerima kekerasan dipengaruhi oleh kondisi-kondisi psikologis. Kondisi psikologis merupakan suatu kondisi yang berasal dari dalam diri korban yang membiarkan dirinya secara terus-menerus mendapatkan kekerasan tanpa adanya penolakan terhadap kekerasan yang ia alami (Djannah, 2003) teutama pada perilaku asertif dan resiliensi (Alizamar, A., Afdal, A., \& Pane, 2019; Afdal et al., 2019). 
Permasalahannya adalah belum ditemukan instrumen/invetori/alat ukur yang valid dan menyeluruh yang dapat mengukur kondisi-kondisi psikologis korban KDRT, kalaupun ada instrumen tersebut adalah bagian-bagian yang terpisahkan dari instrumen-instrumen lainnya. Hasil kajian terdahulu menemukan ada beberapa instrumen kuantitatif telah muncul untuk mengukur kondisi psikologis secara terpisah. Instrumen perilaku asertif individu (Rathus, 1973) mampu menyelidiki keefektifan dari berbagai prosedur untuk membentuk perilaku asertif dan untuk mendapatkan pengukuran sebelum dan sesudah tindakan dari asertif, perilaku asertif untuk perguruan tinggi (Galassi et al., 1974), perilaku asertif pada orang dewasa (Gay et al., 1975). Selanjutnya perilaku asertif untuk orang dewasa secara umum (Hollandsworth et al., 1977), sexual assertiveness untuk mengukur asertif seksual pada wanita yang terdiri dari faktor-faktor inisiasi, penolakan, dan kehamilan (Morokoff et al., 1997). Sedangkan untuk resiliensi instrumen yang telah muncul seperti skala resiliensi untuk mengidentifikasi tingkat resiliensi individu (Wagnild, G. M., \& Young, 1993), The ConnorDavidson Resilience scale (CD-RISC) yang mengukur tentang kemampuan resiliensi dalam mengatasi stress pada komunitas, rawat jalan perawatan primer, rawat jalan psikiatri umum, uji klinis gangguan kecemasan umum dan uji klinis PTSD (Connor \& Davidson, 2003). Skala resiliensi untuk orang dewasa yang mengukur karakteristik pribadi dan protektif serta kekuatan koping yang meningkatkan daya tahan (Friborg et al., 2003). Skala resiliensi untuk menilai kemampuan untuk bangkit kembali atau pulih dari stress (Smith et al., 2008). Selain itu skala resiliensi yang dikembangkan oleh (Pesce, R. P., Assis, S. G., Avanci, J. Q., Santos, N. C., Malaquias, J. V., \& Carvalhaes, 2005) digunakan untuk mengukur tingkat adaptasi psikososial positif. Hanya saja instrument ini dikembangkan berdasarkan lintas budaya Portugis, dan Brazil dianggap kurang cocok untuk di adopsi di Indonesia karena banyak item yang tidak sesuai dengan budaya di Indonesia. Instrumen kekerasan dalam rumah tangga, seperti conflict tactic scale (CST) yang digunakan untuk mengukur tiga dimensi resolusi konflik keluarga: 1) penalaran, 2) agresi verbal, 3) kekerasan (Straus, 1979). Mengukur tentang tekanan subjektif yang terkait dengan peristiwa kehidupan yang traumatis pada remaja dan anak (Horowitz, M., Wilner, N., \& Alvarez, 1979). Secara keseluruhan intrumen yang sudah ada masih terfokus kepada penyebab terjadinya kekerasan secara umum sehingga perlu untuk mengembangkan inventori yang berhubungan dengan kondisi psikologis yang mengakibatkan korban menerima kekerasan.

Berdasarkan kondisi ini, diperlukan inventori yang tepat untuk mengukur kondisi-kondisi psikologis yang mempengaruhi penerimaan KDRT. Tujuan dari penelitian ini adalah untuk mengembangkan dan memvalidasi inventori PAPC-DVI untuk mengetahui kondisi psikologis yang menyebabkan terjadinya penerimaan kekerasan pada korban kekerasan dalam rumah tangga (KDRT). inventori ini sangat perlu dikembangkan dan divalidasi karena belum ada inventori yang valid dan betul-betul bisa mewakili kondisikondisi psikologis yang mempengaruhi penerimaan kekerasan, kalaupun ada variabelnya masih terpisahpisah. Sehingga penting untuk menyusun inventori yang valid dan reliabel. Hasil inventori ini dapat membantu para peneliti, konselor ataupun psikolog dalam mengidentifikasi dan memfasilitasi serta mengenali kondisi-kondisi psikologis yang menyebabkan korban KDRT menerima kekerasan.

\section{Metode}

Penelitian ini dilakukan dengan menggunakan pendekatan penelitian pengembangan (research development). Penelitian pengambangan merupakan suatu proses yang dipakai untuk mengembangkan dan melakukan validasi produk pendidikan (Setyosari, 2013). Penelitian ini dimanfaatkan untuk menghasilkan inventori PAPC-DVI untuk korban KDRT. Ada beberapa prosedur yang dapat digunakan dalam penelitian ini (1) melakukan penelitian dan pengumpulan informasi dengan melakukan kajian pustaka tentang pokok permasalahan, (2) merumuskan tujuan dan menentukan langkah-langkah pengembangan inventori PAPCDVI untuk korban KDRT, (3) mengembangkan produk awal PAPC-DVI untuk korban KDRT dengan menjabarkan variabel menjadi sub variabel, sub variabel menjadi indikator dan indikator menjadi pernyataan inventori, (4) melakukan uji permulaan dengan berkonsultasi kepada ahli untuk meminta masukan dari para ahli. Berkonsultasi dengan para ahli pada penelitian ini dilakukan pada ahli bahasa dan ahli dalam bimbingan dan konseling. (5) melakukan revisi inventori PAPC-DVI untuk korban KDRT berdasarkan masukan dari para ahli pada tahap uji permulaan, (6) melakukan uji coba kelapangan untuk menguji validitas dan reliabilitas inventori PAPC-DVI untuk korban KDRT, (7) melakukan revisi produk operasional inventori PAPC-DVI berdasarkan hasil uji coba lapangan.

Sampel pada penelitian sebanyak 90 orang istri korban KDRT yang mengalami kekerasan dan berdomisili di kota Padang dengan menggunakan teknik pengambilan sampel purposive sampling. Adapun data demografi sampel dapat dilihat pada tabel 1 berikut. 
Tabel 1. Data demografi sampel penelitian

\begin{tabular}{lcc}
\hline $\begin{array}{l}\text { Lama Pernikahan } \\
\text { (orang) }\end{array}$ & $\begin{array}{c}\text { Latar Belakang Budaya } \\
\text { (orang) }\end{array}$ & $\begin{array}{c}\text { Status Sosial Ekonomi } \\
\text { (orang) }\end{array}$ \\
\hline $\mathbf{1 0}$ tahun ke atas, $\mathbf{n}=\mathbf{4 0}$ & Budaya Minang, $\mathrm{n}=59$ & Ekonomi Tinggi, $\mathrm{n}=36$ \\
$\mathbf{5 - 1 0}$ tahun, $\mathbf{n}=\mathbf{2 5}$ & Budaya Non Minang= 31 & Ekonomi Sedang, $\mathrm{n}=35$ \\
$\mathbf{5}$ tahun ke bawah, $\mathbf{n}=\mathbf{2 5}$ & & Ekonomi Rendah, $\mathrm{n}=19$ \\
\hline
\end{tabular}

Inventori PAPC-DVI akan mengukur perilaku asertif dan resiliensi. Untuk mengukur perilaku asertif dikembangkan menggunakan teori Galassi (1974) yang mengukur positive assertiveness, self-afirmation dan negative assertiveness, sedangkan untuk resiliensi dikembangkan menggunakan teori Wagnild (2009) yang mengukur equaminity, perseverance, self-reliance, meaningfulness dan existential aloneness. Instrumen yang digunakan dalam penelitian ini berupa model skala Likert dengan lima pilihan jawaban yakni sangat sesuai (5), sesuai (4) cukup sesuai (3), tidak sesuai (2) dan sangat tidak sesuai (1). Data yang diperoleh dianalisis menggunakan analisis validitas dan reliabilitas. Uji validitas dilakukan dengan menggunakan analisis item Alpha Cronbach (Csikszentmihalyi \& Larson, 2014) untuk menentukan korelasi setiap item terhadap skor total dengan kriteria berdasarkan tabel $\mathrm{r}$ dengan $\mathrm{n} 90$ pada taraf signifikan, $05 \alpha \geq, 175$. Analisis ini dianggap efektif untuk mengukur validitas konstruk suatu instrument jika item-itemnya valid. Selain itu, uji reliabilitas dilakukan dengan menentukan konsistensi PAPC-DVI dalam menganalisis ulang tanpa ada item yang dihilangkan.

\section{Hasil dan Pembahasan}

Pengembangan dilakukan dengan menjabarkan sub variabel menjadi indikator dan indikator menjadi item pernyataan sebanyak 36 item yang terdiri atas pernyataan positif dan negatif, lalu dilakukan uji permulaan dengan cara berkonsultasi dengan para ahli. Hasilnya terdapat pernyataan yang perlu direvisi mulai dari penggunaan bahasa dan pernyataan yang belum mengungkapkan aspek inventori PAPC-DVI yang diharapkan sehingga perlu disempurnakan. Setelah dilakukan revisi sesuai masukan dari para ahli langkah selanjutnya adalah melakukan uji coba lapangan untuk mengukur validitas dan keandalan inventori PAPC-DVI bagi korban KDRT.

Hasil uji coba ini kemudian dianalisis menggunakan analisis validitas dan reliabilitas item. Untuk analisis validitas, pengembangan dan validasi inventori PAPC-DVI diuji dengan menganalisis tingkat presisi kemampuannya untuk mengukur konstruk/ indikator/ variabel. Untuk mengetahui validitas instrumen ditentukan oleh perbedaan skor item dengan skor total. Analisis ini secara efektif digunakan dalam mengukur validitas dan reliabilitas skala Likert. Hasil yang diperoleh terdapat pada tabel 2.

Tabel 2. Hasil analisis validitas per item

\begin{tabular}{|c|c|c|}
\hline $\begin{array}{l}\text { No. } \\
\text { Item }\end{array}$ & Pernyataan & $\begin{array}{l}\text { Pearson } \\
\text { Correlation }\end{array}$ \\
\hline \multicolumn{3}{|c|}{ Positive Assertiveness } \\
\hline 1 & Mengucapkan selamat kepada suami atas prestasi yang diperolehnya & ,536 \\
\hline 2 & Merasa senang ketika suami makan masakan saya secara lahap & , 470 \\
\hline 3 & Merasa malu untuk memberikan pujian kepada suami & ,776 \\
\hline 4 & Menawarkan bantuan kepada suami ketika suami mengalami kesulitan & ,468 \\
\hline 5 & $\begin{array}{l}\text { Tidak membutuhkan pertolongan orang lain dalam menghadapi situasi yang } \\
\text { bisa saya selesaikan sendiri }\end{array}$ & ,361 \\
\hline 6 & Berani mengekspresikan perasaan agar orang lain memahami kondisi saya &, 510 \\
\hline 7 & Merasa suami cepat bosan ketika terlibat pembicaraan yang lama & ,539 \\
\hline \multicolumn{3}{|c|}{ Self-Affirmation } \\
\hline 8 & $\begin{array}{l}\text { Beranggapan bahwa seorang istri tidak berhak mempertahankan haknya } \\
\text { karena harus patuh kepada suami }\end{array}$ & ,377 \\
\hline 9 & Mengorbankan hak pribadi demi kepentingan suami & ,599 \\
\hline 10 & $\begin{array}{l}\text { Merasa kesulitan untuk mengatakan "tidak" ketika menolak permintaan } \\
\text { suami }\end{array}$ & ,659 \\
\hline 11 & Mampu menolak ajakan suami dengan tegas tanpa melukai perasaannya & ,446 \\
\hline
\end{tabular}




\begin{tabular}{|c|c|c|}
\hline $\begin{array}{l}\text { No. } \\
\text { Item }\end{array}$ & Pernyataan & $\begin{array}{c}\text { Pearson } \\
\text { Correlation }\end{array}$ \\
\hline 12 & Dengan senang hati menyampaikan pendapat ketika diminta oleh suami & ,362 \\
\hline 13 & $\begin{array}{l}\text { Ketika menyampaikan pendapat, saya merasa suami tidak mendengarkannya } \\
\text { dengan sungguh-sungguh }\end{array}$ & 461 \\
\hline \multicolumn{3}{|c|}{ Negative Assertiveness } \\
\hline 14 & $\begin{array}{l}\text { Tidak segan-segan untuk mengungkapkan ketidaksenangan saya kepada } \\
\text { suami }\end{array}$ & ,492 \\
\hline 15 & Berusaha untuk menjaga perasaan suami ketika menyampaikan kekecewaan &, 516 \\
\hline 16 & Ketika suami memarahi saya tanpa alasan, saya membalas memarahinya &, 514 \\
\hline 17 & Ketika marah, saya berusaha untuk tetap mengontrol emosi & 629 \\
\hline \multicolumn{3}{|c|}{ Equaminity } \\
\hline 18 & Apapun alasannya, saya tidak mau lagi diperlakukan kasar oleh siapapun & ,391 \\
\hline 19 & Merasa putus asa karena sering menerima kekerasan & 579 \\
\hline 20 & Merasa dengan bercanda tawa membuat saya bisa melupakan kesedihan & 475 \\
\hline 21 & Jika saya sedih, saya akan sulit untuk ceria kembali & ,409 \\
\hline \multicolumn{3}{|c|}{ Perseverance } \\
\hline 22 & $\begin{array}{l}\text { Kegigihan saya untuk terlepas dari kesulitan sangat bergantung pada suasana } \\
\text { hati }\end{array}$ &, 575 \\
\hline 23 & Ketika saya gagal, saya berusaha untuk bangkit kembali & 701 \\
\hline 24 & Memiliki kemampuan disiplin yang baik & 499 \\
\hline 25 & Melanggar komitmen yang telah saya buat & 437 \\
\hline \multicolumn{3}{|c|}{ Self-reliance } \\
\hline 26 & Meragukan kemampuan saya untuk menyelesaikan masalah & ,639 \\
\hline 27 & $\begin{array}{l}\text { Ketika menemukan kesulitan, saya dapat memikirkan banyak cara untuk } \\
\text { keluar dari permasalahan }\end{array}$ & ,621 \\
\hline 28 & $\begin{array}{l}\text { Kemampuan saya dalam menghadapi kesulitan dimasa lalu membuat saya } \\
\text { yakin untuk bisa melewati kesulitan dimasa mendatang }\end{array}$ & ,677 \\
\hline 29 & Ketika membuat keputusan, saya tidak bergantung pada orang lain & ,475 \\
\hline 30 & Sangat bergantung pada arahan orang lain dalam kehidupan sehari-hari & ,496 \\
\hline \multicolumn{3}{|c|}{ Meaningfulness } \\
\hline 31 & Memiliki target dalam mencapai tujuan hidup & ,469 \\
\hline 32 & $\begin{array}{l}\text { Kekerasan yang saya alami membuat saya kehilangan harapan untuk } \\
\text { mencapai target yang telah ditetapkan }\end{array}$ & 650 \\
\hline \multicolumn{3}{|c|}{ Exitential Aloneness } \\
\hline 33 & Menyadari bahwa setiap orang memiliki karakter yang berbeda & ,477 \\
\hline 34 & Merasa perbedaan yang mengakibatkan terjadinya kekerasan &, 579 \\
\hline 35 & Bisa berdamai dan bersahabat dengan diri saya sendiri & ,444 \\
\hline 36 & $\begin{array}{l}\text { Merasa orang lain sulit untuk menerima keadaan saya yang pernah } \\
\text { mengalami kekerasan }\end{array}$ &, 518 \\
\hline
\end{tabular}

Hasil pada tabel 1 menunjukkan bahwa koefisien $\alpha$ pada taraf signifikansi $05>, 175$ yang berarti semua item adalah valid. Penelitian ini menggunakan metode reliabilitas internal untuk menentukan keandalan instrumen. Reliabilitas internal dapat ditentukan dengan menganalisis dari satu kali pengujian. Tabel 3 menunjukkan reliabilitas pengembangan inventori PAPC-DV dengan menggunakan rumus Alpha Cronbach.

Hasil perhitungan pada Tabel 3 untuk reliabilitas diperoleh nilai koefisien alpha cronbach sebesar 0,932. Berdasarkan tolak ukur dalam menginterpretasikan derajat dengan menggunakan derajat reliabilitas nilai alpha cronbach 0,932 masuk dalam kategori sangat tinggi (Arikunto, 2010) sehingga inventori PAPC-DVI dapat dikatakan reliabel. Hasil penelitian juga menunjukan bahwa pengembangan skala ekspresi diri pada orang dewasa memiliki skala reliabilitas pengujian tes ulang yang tinggi dan validitas konstruk sedang hingga tinggi, sebagaimana yang ditetapkan oleh korelasi dengan skala daftar periksa adjective dan oleh analisis prosedur analisis diskriminan (Gay et al., 1975). Perilaku asertif istri terhadap pasangan cenderung untuk mencegah kekerasan dalam rumah tangga sehingga membuat hubungan menjadi lebih dekat, karena semakin tinggi perilaku asertif maka semakin besar tingkat kepuasan pernikahan terhadap pasangan yang 
menikah dan sebaliknya (Astuti et al., 2019). Dala, (2019) menyatakan bahwa individu dengan resiliensi yang baik adalah individu yang optimis, yang percaya bahwa segala sesuatu dapat berubah menjadi lebih baik. Individu mempunyai harapan terhadap masa depan dan percaya bahwa individu dapat mengontrol arah kehidupan. Optimis membuat fisik menjadi lebih sehat dan mengurangi kemungkinan menderita depresi. Untuk alasan ini, perlu untuk memiliki alat pengukur untuk mengukur kondisi-kondisi psikologis yang mempengaruhi penerimaan kekerasan pada korban KDRT, sehingga orang dapat melakukan identifikasi kondisi-kondisi psikologis yang menyebabkan korban KDRT menerima kekerasan.

Tabel 3. Hasil Analisis Reliabilitas

\begin{tabular}{cc}
\hline & Reliability Statistics \\
Cronbach's Alpha & N of Items \\
, 932 & 36 \\
\hline
\end{tabular}

Instrumen yang baik harus memenuhi kriteria validitas dan reliabilitas. Validitas adalah sejauh mana instrumen dapat mengukur apa seharusnya yang diukur (Siregar, 2014; Sugiyono, 2011). Selain itu reliabilitas merupakan karakteristik yang penting dalam setiap tes, untuk itu instrumen harus valid dan reliabel sehingga bisa digunakan sebagai alat ukur (Susanto, 2016). Oleh karena itu, pengembangan dan validasi inventori PAPC-DVI dapat digunakan sebagai alat ukur untuk mengungkapkan kondisi psikologis yang mengakibatkan korban KDRT menerima kekerasan karena telah memenuhi kritia sebagai alat ukur.

\section{Kesimpulan}

Hasil uji validitas dan reliabilitas pengembangan dan validasi inventori PAPC-DVI bagi korban KDRT menunjukkan bahwa inventori ini terdiri atas 36 item dengan koefisien reliabilitas sebesar 0,932. Dengan demikian dapat disimpulkan bahwa pengembangan inventori PAPC-DVI bagi korban KDRT memiliki koefisien yang tinggi dengan menunjukkan 36 item yang valid dan reliabel. Dengan demikian instrumen tersebut dapat digunakan dalam penelitian selanjutnya, terutama dalam mengukur kondisi-kondisi psikologis korban kekerasan dalam rumah tangga.

\section{Referensi}

Afdal. (2015). Pemanfaatan konseling keluarga eksperensial untuk penyelesaian kasus kekerasan dalam rumah tangga. Indonesia, Jurnal Pendidikan, 1, 76-79.

Afdal, A., Sari, P. F., Fikri, M., Ifdil, I., \& Ardi, Z. (2019). Why Victims of Domestic Violence Still Survive Their Marriage? Preliminary Analysis of Forgiveness Dynamics Conditions. International Journal of Research in Counseling and Education, 3(2), 125-130.

Alizamar, A., Afdal, A., \& Pane, N. (2019). Non Psychological Conditions that Influence The Acceptance of Violence On Victims Of Domestic Violence : A Narrative Review. International Journal of Research in Counseling and Education, 3(2), 115-119. https://doi.org/10.24036/00168za0002

Anggoman, Y., \& Wirawan, H. (2002). Dampak Psikologis Kekerasan Fisik di Dalam Rumah Tangga. Jurnal Ilmiah Psikologi "ARKHE, 7(2), 91-99.

Arikunto, S. (2010). Prosedur Penelitian Suatu pendekatan Praktek. Jakarta: Rineka Cipta.

Astuti, A. D., Alizamar, A., \& Afdal, A. (2019). Assertive behaviour difference among domestic violence victims. Journal of Educational and Learning Studies, 2(2), 83-87. https://doi.org/10.32698/0602

Ayu, I. D., Puspita, D., \& Hartini, N. (2017). Dinamika Forgiveness pada Istri yang Mengalami Kekerasan dalam Rumah Tangga ( KDRT ). Jurnal Psikologi Dan Kesehatan Mental, 2(1), 51-62. https://doi.org/10.20473/jpkm.v2i12017.51-62

Benjamin J. Sadock, M. ., \& Virginia A. Sadock, M. (2005). Kaplan and Sadock's Comprehensive Textbook Of Psychiatry (Lippincott).

Chosniah, J. (2014). Komitmen Perempuan Korban Kdrt Sebelum Membuat Keputusan Menikah. Universitas Muhammadiyah Jember.

Connor, K. M., \& Davidson, J. R. T. (2003). Development of a new resilience scale: The Connor- Davidson resilience scale (CD- RISC). Depression and Anxiety, 18(2), 76-82.

Csikszentmihalyi, M., \& Larson, R. (2014). Validity and reliability of the experience-sampling method. In Flow and the foundations of positive psychology (pp. 35-54). Springer.

Dala, S. A. U. (2019). Resiliensi Pada Istri Korban Kekerasan Dalam Rumah Tangga. Mercu Buana, Yogyakarta. 
Djannah, F. (2003). Kekerasan Terhadap Istri. Jakarta: PT LKiS Pelangi Aksara.

Friborg, O., Hjemdal, O., Rosenvinge, J. H., \& Martinussen, M. (2003). A new rating scale for adult resilience: what are the central protective resources behind healthy adjustment? International Journal of Methods in Psychiatric Research, 12(2), 65-76.

Galassi, J. P., Delo, J. S., Galassi, M. D., \& Bastien, S. (1974). The college self-expression scale: A measure of assertiveness. Behavior Therapy, 5(2), 165-171. https://doi.org/10.1016/S0005-7894(74)80131-0

Gay, M. L., Hollandsworth, J. G., \& Galassi, J. P. (1975). An assertiveness inventory for adults. Journal of Counseling Psychology, 22(4), 340-344. https://doi.org/10.1037/h0076706

Hollandsworth Jr, J. G., Galassi, J. P., \& Gay, M. L. (1977). The adult self expression scale: Validation by the multitrait- multimethod procedure. Journal of Clinical Psychology, 33(2), 407-415. https://doi.org/10.1002/aja.1000860102

Horowitz, M., Wilner, N., \& Alvarez, W. (1979). Impact of Events Scale: A measure of subjective stress. Psychosomatic Medicine, 41, 209-218.

Komnas Perempuan. (2020). Kekerasan Meningkat: Kebijakan Penghapusan Kekerasan Seksual untuk Membangun Ruang Aman bagi Perempuan dan Anak Perempuan. In Komnas Perempuan. https://www.komnasperempuan.go.id/file/pdf_file/2020/Catatan Tahunan Kekerasan Terhadap Perempuan 2020.pdf

Luhulima, A. S. (2000). Pemahaman Bentuk-Bentuk Tindak Kekerasan Terhadap Perempuan dan Altematif Pemecahannya. Jakarta: Alumni.

Lundberg-Love, P. K., Marmion, S. L., \& Marmion, S. (2006). “Intimate” violence against women: when spouses, partners, or lovers attack. Greenwood Publishing Group.

Morokoff, P. J., Quina, K., Harlow, L. L., Whitmire, L., Grimley, D. M., Gibson, P. R., \& Burkholder, G. J. (1997). Sexual Assertiveness Scale (SAS) for women: Development and validation. Journal of Personality and Social Psychology, 73(4), 790-804. https://doi.org/10.1037/0022-3514.73.4.790

Nurhayati, S. R. (2006). Peningkatan Kemampuan Menggunakan Problem Focused Coping Perempuan Korban Kekerasan Dalam Rumah Tangga. Universitas Negeri Yogyakarta.

Pesce, R. P., Assis, S. G., Avanci, J. Q., Santos, N. C., Malaquias, J. V., \& Carvalhaes, R. (2005). rosscultural adaptation, reliability and validity of the resilience scale. Cadernos de Saude Publica, 21(2), 436448.

Rathus, S. A. (1973). A 30-item schedule for assessing assertive behavior. Behavior Therapy, 4(3), $398-406$. https://doi.org/10.1016/S0005-7894(73)80120-0

Segaf, Z., Yumpi-R, F., \& H, P. K. (2009). Memahami Alasan Perempuan Bertahan Dalam Kekerasan Domestik. Insight: Jurnal Pemikiran Dan Penelitian Psikologi, 5(1), $30-47$. http://jurnal.unmuhjember.ac.id/index.php/INSIGHT/article/view/seg/1199

Setyosari, P. (2013). Metode Penelitian: Pendidikan \& pengembangan. Jakarta: Kencana Prenada Group.

Siregar, S. (2014). Statistik Parametrik Penelitian Kuantiatif: Dilengkapi Dengan Perhitungan Manual dan Aplikasi SPSS Versi 20. Jakarta: Bumi Aksara.

Smith, B. W., Dalen, J., Wiggins, K., Tooley, E., Christopher, P., \& Bernard, J. (2008). The brief resilience scale: Assessing the ability to bounce back. International Journal of Behavioral Medicine, 15(3), 194-200. https://doi.org/10.1080/10705500802222972

Soemarno, D. S., Imelia, L., Psi, M., Psikologi, F., \& Maranatha, U. K. (2017). Studi Deskriptif Mengenai Dimensi-dimensi Psychological Well-being Pada Istri Korban Kekerasan dalam Rumah Tangga di Yayasan JaRI Kota Bandung.

Sriyanto, -, Abdulkarim, A., Zainul, A., \& Maryani, E. (2014). Perilaku Asertif dan Kecenderungan Kenakalan Remaja Berdasarkan Pola Asuh dan Peran Media Massa. Jurnal Psikologi, 41(1), 74. https://doi.org/10.22146/jpsi.6959

Straus, M. A. (1979). Measuring intrafamily conflict and violence: The conflict tactics (CT) scales. Journal of Marriage and the Family, 75-88.

Sugiyono. (2011). Metode Penelitian Kuantitatif dan Kualitatif. Jakarta: Alfabeta.

Susanto, H. (2016). The Effect of Crossword Puzzle on The Students' Vocabulary Mastery at Second Grade of Muhammadiyah Junior High School of Palangka Raya. (Doctoral Dissertation) IAIN Palangka Raya.

Twenge, J. M. (2001). Changes in women's assertiveness in response to status and roles: A cross-temporal meta-analysis, 1931-1993. Journal of Personality and Social Psychology, 81(1), 133.

Wagnild, G. M., \& Young, H. (1993). Development and Psychometric Evaluation of the Resilience Scale. In Journal of nursing measurement (Vol. 2, Issue 2, pp. 165-178). https://doi.org/10.1080/08927936.2018.1406203

Wagnild, G. (2009). A review of the resilience Scale. Journal of Nursing Measurement, 17(2), $105-113$. https://doi.org/10.1891/1061-3749.17.2.105 